\title{
Eleutheroside K Isolated from Acanthopanax henryi (Oliv.) Harms Inhibits the Expression of Virulence-Related Exoproteins in Methicillin-Resistant Staphylococcus aureus
}

\author{
Qian-Qian Li ${ }^{1}$. Jiao Luo ${ }^{2}$ Xiang-Qian Liu ${ }^{2}$ Ok-Hwa Kang ${ }^{1}$. Dong-Yeul Kwon ${ }^{1}$
}

Received: 3 April 2021 / Accepted: 5 August 2021 / Published online: 23 September 2021

(C) The Author(s) 2021

\begin{abstract}
Methicillin-resistant Staphylococcus (S.) aureus (MRSA) is a representative pathogen that produces numerous virulence factors involving manifold cytotoxins and exotoxins. The present study was designed to investigate the influence of Eleutheroside K (ETSK), a single compound isolated from the leaves of Acanthopanax (A.) henryi (Oliv.) Harms, on the exotoxins secreted by MRSA. The transcription and translation of the exotoxins ( $\alpha$-hemolysin and staphylococcal enterotoxins) related to virulence in S. aureus were determined via quantitative RT-PCR and western blot analysis. The effect of ETSK on the production of tumor necrosis factor (TNF)- $\alpha$ was evaluated using enzyme-linked immunosorbent assay. As a result, ETSK at sub-MIC concentrations could reduce the protein expression of $\alpha$-hemolysin and enterotoxin, and the expression of genes that regulate virulence factors was also inhibited. In addition, the TNF-inducing activity of S. aureus was attenuated by ETSK in a dose-dependent manner. These results revealed that ETSK not only reduced the protein and gene expression levels of related exotoxins but also suppressed the ability of $S$. aureus to induce macrophages to release cytokines. This study indicated that the inhibition of MRSA infection by ETSK may be achieved by reducing the virulence of $S$. aureus and highlighted the potential of ETSK as an innovative strategy for the prevention and treatment of MRSA infections.
\end{abstract}

\section{Introduction}

Staphylococcus $(S$.$) aureus is a causal organism implicated$ in considerable opportunistic infections, colonizing humans and animals [1]. It is a substantial contributor to a variety of invasive infectious diseases and can penetrate the subcutaneous tissues to reach the blood [2]. In order to inhibit bacterial growth, numerous antibiotics have been developed and used to treat $S$. aureus infections [3]. However, the efficacy of antibiotics was limited by the emergence of methicillin-resistant $S$. aureus (MRSA) [4, 5]. Since MRSA is recognized as one of the major causes of healthcare- and

Ok-Hwa Kang

kangokhwa@daum.net

$\triangle$ Dong-Yeul Kwon

sssimi@wku.ac.kr

1 Department of Oriental Pharmacy, College of Pharmacy and Wonkwang Oriental Medicines Research Institute, Wonkwang University, Iksan, Jeonbuk 54538, Republic of Korea

2 School of Pharmacy, Hunan University of Chinese Medicine, Changsha 410-208, Hunan, People's Republic of China community-associated infections and is a serious menace that frequently occurs all over the world, the treatment of S. aureus infections becomes complicated $[6,7]$. The community is facing a huge challenge, and MRSA infection is especially concerning. The pathogenicity of MRSA is predominantly attributed to the toxin production and drug resistance. Exploring drugs that can interfere with the synthesis of bacterial virulence factors may be a countermeasure against MRSA infection [8].

Several $S$. aureus exotoxins produced by MRSA can exacerbate the symptoms of MRSA infections and play a crucial role in the pathogenesis, including hemolysins, enterotoxins, toxic shock syndrome toxin 1 (TSST-1) and panton-valentine leukocidin (PVL) [9]. These toxins are related to the increased inflammation and disease severity of $S$. aureus infection. In this study, we mainly focused on the exotoxin genes and virulence proteins, including $\alpha$-hemolysin and staphylococcal enterotoxins (SEs) produced by MRSA. The expression of multiple virulence factors produced by $S$. aureus is strictly regulated. The global regulatory systems such as accessory gene regulators (agr) system control the expression of $S$. aureus toxins [10]. The agr locus is considered to be the quorum-sensing 
system of $S$. aureus, and RNAII is the operon of agrBDCA driven by promoter 2 (P2). AgrB is encoded as a transmembrane endopeptidase and is responsible for the processing and export of $\mathrm{AgrD}$, which is the precursor of autoinducer peptide (AIP). At a threshold concentration, AIP binds to AgrC to autophosphorylate AgrC and subsequently phosphorylate AgrA. The activated AgrA triggers P3-driven transcription followed by translation of RNAIII [11]. RNAIII is the main effector of $a g r$ system, which can positively regulate the expression of $\alpha$-hemolysin and SEs [12].

Previous studies have reported that bacterial virulence factors mediate $S$. aureus-associated infections [13]. Multiple proteins such as $\alpha$-hemolysin and enterotoxins are predominant virulence factors secreted by $S$. aureus strains. The $\alpha$-hemolysin produced by most pathogenic strains of S. aureus is a $33-\mathrm{kDa}$ pore-forming toxin that exhibits dermonecrotic, cytolytic, hemolytic, and lethal activities [14]. The SEs secreted by certain $S$. aureus strains can induce staphylococcal gastroenteritis and lead to food poisoning in humans [15]. At the transcriptional level, $\alpha$-hemolysin, SEA, and SEB are coded by hla, sea, and seb, respectively [16]. Moreover, the $a g r$ are recognized as a distinct global regulatory system that encodes the gene expression of manifold virulence factors [17]. In addition, SEs stimulate $\mathrm{T}$-cell activation to release $\mathrm{T}$ cell-derived cytokines [14]. Cytokines such as interleukin-6 and tumor necrosis factor (TNF)- $\alpha$ exhibit pro-inflammatory effects in multiple inflammatory disorders [18]. It has been reported that MRSA has the potential to up-regulate the pro-inflammatory levels of TNF- $\alpha$ secreted by macrophages [19].

To address the intractable infections, the unique research idea of studying the antibacterial effects of naturally occurring compounds may lead to a novel treatment strategy. Acanthopanax (A.) henryi (Oliv.) Harms belongs to family Araliaceae and is widely distributed in China, Korea, and Japan. A. henryi (Oliv.) Harms has been used extensively as a traditional oriental medicine to treat rheumatism and cancer [20]. According to reports, the root bark of $A$. henryi has significant anti-inflammatory activity, while the leaves of $A$. henryi possess anti-oxidant activity [21, 22]. Various bioactive ingredients have been extracted from A. henryi (Oliv.) Harms [23]. The present study focused on Eleutheroside K (ETSK) (Suppl. Fig. 1), one of the bioactive compounds extracted from the leaves of $A$. henryi, as a latent therapeutic agent to eliminate bacterial virulence factors, so as to achieve the purpose of inhibiting MRSA infection. There are few studies on the pharmacological activity of ETSK. By determining the antibacterial susceptibility, our previous studies confirmed the pharmacological mechanism of ETSK reversing the methicillin resistance caused by MRSA and displayed a minimal inhibitory concentration of $50 \mu \mathrm{g} /$ $\mathrm{mL}$ [24]. In this context, the antibacterial ability of ETSK will be further investigated by analyzing the effect of ETSK on the secretion of staphylococcal virulence factors in vitro.

\section{Materials and Methods}

\section{Plant Collection}

The leaves of $A$. henryi (Oliv.) Harms were collected in October 2012 at Xinhua (Changsha, China). The plant species was confirmed by Professor Xiang-Qian Liu (Hunan Key Laboratory of Traditional Chinese Medicine Modernization, Hunan University of Chinese Medicine, Changsha, China) and the voucher specimen (No. 20121125) was deposited at the School of Pharmacy, Hunan University of Chinese Medicine.

\section{Extraction and Isolation}

The dried leaves of $A$. henryi (Oliv.) Harms (10 kg) were extracted with methanol and the resulting extract was partitioned between petroleum ether and $\mathrm{H}_{2} \mathrm{O}$. The fractionation of water fraction was done using column chromatography (CC) on macroporous resin. Finally, the water fraction was eluted into five fractions under a gradient of $\mathrm{EtOH} / \mathrm{H}_{2} \mathrm{O}(0$, $30,50,75$, and $95 \%)$. Fraction $4(75 \% \mathrm{EtOH}, 14.0 \mathrm{~g})$ was subjected to various CC [silica gel, Sephadex LH-20, and reverse-phase octadecylsilyl (ODS) preparative high-performance liquid chromatography (HPLC)] to obtain compound ETSK [25]. The structure of ETSK was identified using mass spectroscopy, 1D nuclear magnetic resonance (NMR), and 2D NMR. As previously described, the purity of ETSK determined by HPLC was $>98 \%$ [18].

\section{Reagents}

Difco $^{\text {TM }}$ Mueller-Hinton agar (MHA), Difco ${ }^{\text {TM }}$ Mueller-Hinton broth (MHB), and Difco ${ }^{\mathrm{TM}}$ skim milk were obtained from Difco Laboratories (Baltimore, MD, USA). Glycerol was obtained from Sigma-Aldrich; Merck KGaA (Darmstadt, Germany). Power SYBR® Green PCR master mix was purchased from Applied Biosystems (Warrington, UK). SMART ${ }^{\mathrm{TM}}$ bacterial protein extraction solution was purchased from Intron Biotechnology Inc. (Seongnam, Korea). Mouse TNF (Mono/Mono) ELISA set and the 3, 3', 5, 5'-tetramethyl benzidine (TMB) Substrate Reagent Set was purchased from BD OptEIA ${ }^{\mathrm{TM}}$ (BD Biosciences, San Diego, CA92121, USA).

\section{Bacterial Strains and Culture Medium}

MRSA strain ATCC 33,591 was purchased from the American Type Culture Collection (Manassas, VA, USA). ATCC 
33,591 was cultured on either MHA or MHB at $37^{\circ} \mathrm{C}$ for $24 \mathrm{~h}$ for experimental use. The bacteria were stored in $30 \%$ glycerol and frozen at $-80{ }^{\circ} \mathrm{C}$.

\section{RNA Extraction and Quantitative Real-Time Reverse Transcription Polymerase Chain Reaction (qRT-PCR)}

Real-time RT-PCR was performed as previously described [26]. In our previous experiment, it has been determined that the minimum inhibitory concentration of ETSK against ATCC 33,591 is $50 \mu \mathrm{g} / \mathrm{mL}$ [24]. The ATCC 33,591 strain was grown to an absorbance value of 0.9 at an optical density $600 \mathrm{~nm}\left(\mathrm{OD}_{600 \mathrm{~nm}}\right)$ and treated with sub-inhibitory concentrations $(6.25-25 \mu \mathrm{g} / \mathrm{mL})$ of ETSK for $4 \mathrm{~h}$ [26]. Bacterial cells were pelleted by centrifugation at $13,000 \mathrm{~g}$ for $10 \mathrm{~min}$. Total RNA was prepared using the E.Z.N.A.® bacterial RNA kit (OMEGA Bio-Tek, Norcross GA, USA) according to the manufacturer's protocol. The mRNA concentrations were measured using Nanodrop spectrophotometer (Bio-Tek, Winooski, VT, USA), and equal mRNA amounts $(1 \mu \mathrm{g})$ were adjusted using gDNA Wipeout Buffer and RNase-free water according to the calculated mRNA concentrations. The QuantiTect reverse transcription kit (Qiagen, Seoul, Korea) was used to reverse transcribe mRNA into the first-strand complementary DNA (cDNA), and $14 \mu \mathrm{L}$ sample mRNA, $1 \mu \mathrm{L}$ reverse transcriptase (RT), $1 \mu \mathrm{L}$ gene-specific primers $(0.7 \mu \mathrm{M})$, and $4 \mu \mathrm{L}$ RT buffer were mixed to obtain sample cDNA. Components needed to run PCR were set up as follows: $2 \mu \mathrm{L}$ sample cDNA, $10 \mu \mathrm{L}$ SYBR master mix, $1 \mu \mathrm{L}$ of each primer $(10 \mu \mathrm{M})$, and $6 \mu \mathrm{L}$ deionized water to a total volume of $20 \mu \mathrm{L}$. The primer pairs used to synthesize the DNA template for qRT-PCR are presented in Suppl. Table 1. The quantitative PCR was run using the StepOnePlus realtime PCR system (Applied Biosystems, France).

\section{Protein Extraction and Western Blotting Analysis}

The western blot was performed as described previously to measure protein translation levels [26]. ATCC 33,591 suspensions $\left(\mathrm{OD}_{600 \mathrm{~nm}}\right.$ value of 0.9$)$ were treated with graded sub-inhibitory concentrations $(6.25-25 \mu \mathrm{g} / \mathrm{mL})$ of ETSK. Bacterial cells were harvested after $4 \mathrm{~h} \mathrm{[26]} \mathrm{and}$ suspended in bacterial protein extraction solution according to the manufacturer's instructions. Bacterial lysates were centrifuged at $13,000 \times g$ for $10 \mathrm{~min}$ to remove the insoluble fractions. Equal protein amounts were measured using Bio-Rad protein assay reagent (Bio-Rad Laboratories, Inc., Hercules, CA, USA) to perform the sodium dodecyl sulfate-polyacrylamide gel electrophoresis (SDS-PAGE). The electrophoresed gels were transferred to Amersham ${ }^{\mathrm{TM}}$ Hybond ${ }^{\mathrm{TM}}$-P-membranes (GE Healthcare, Piscataway, NJ, USA). The membranes were blocked in Tris-buffered saline with Tween 20 (TBST) containing 5\% skim milk and then probed with polyclonal rabbit anti-Staphylococcus alphahemolysin antibody (Abcam, UK), polyclonal rabbit antiStaphylococcus Enterotoxin A antibody ab 15,897 (Abcam, UK), and polyclonal rabbit anti-Staphylococcus Enterotoxin B antibody ab 15,898 (Abcam, UK). The loading differences were normalized with mouse monoclonal anti-glyceraldehyde 3-phosphate dehydrogenase (GAPDH) antibody (Cell signaling technology, USA). The membranes were incubated overnight at $4{ }^{\circ} \mathrm{C}$. After washing three times, membranes were re-probed with goat anti-rabbit IgG secondary antibody (Thermo Scientific, USA) and anti-mouse IgG secondary antibody (Enzo Life Sciences, USA) for $2 \mathrm{~h}$. The membranes were then supplemented with TOPview ${ }^{\mathrm{TM}} \mathrm{ECL}$ Femto Western Substrate (Enzynomics, Korea). Imagequant LAS-4000 mini chemical luminescent imager (GE Healthcare Life, Korea) was used to detect the immunoreactive bands of membranes.

\section{Enzyme-Linked Immunosorbent Assay (ELISA)}

ATCC $33,591\left(\mathrm{OD}_{600 \mathrm{~nm}}\right.$ value of 0.3$)$ was grown by shaking overnight in MHB with graded concentrations of ETSK $(1 / 8,1 / 4$, and $1 / 2 \times$ MIC). Untreated bacteria were used as a control. After centrifuging at $4000 \mathrm{~g}$ for $10 \mathrm{~min}$, the collected supernatants (protein secretions) were filtered through $0.45 \mu \mathrm{M}$ micro filters. While, RAW 264.7 cells were seeded at a density of $10^{6} / \mathrm{mL}$ in RPMI 1640 (supplemented with $10 \%$ FBS, $100 \mathrm{IU} / \mathrm{mL}$ penicillin, and streptomycin). The cell suspension $(100 \mu \mathrm{L})$ was dispensed into a 96-well cell culture plate and then incubated at $37{ }^{\circ} \mathrm{C}$ in an incubator $(5 \%$ $\mathrm{CO}_{2}$ ) for $18 \mathrm{~h}$ to make cells adhere. When cells adhered to the bottom of the plate, cell culture media were replaced with fresh RPMI 1640 medium $(150 \mu \mathrm{L})$. The filtered $S$. aureus supernatants $(50 \mu \mathrm{L})$ were added to the corresponding wells. Fresh RPMI was used instead of bacterial supernatant as normal blank control group. After incubation for $24 \mathrm{~h}$, the culture medium of RAW 264.7 cells was collected in $1.5 \mathrm{~mL}$ tubes and centrifuged $(13,000 \mathrm{~g}$ for $5 \mathrm{~min})$ to obtain the supernatant samples.

The tumor necrosis factor (TNF) level was measured using the OptEIA ${ }^{\mathrm{TM}}$ mouse TNF (Mono/Mono) ELISA set according to the manufacturer's instructions. The required wells of 96-well plate were coated with the capture antibody diluted in coating buffer $(1: 250)$, then the plate was sealed, and incubated overnight at $4{ }^{\circ} \mathrm{C}$. After washing each well with phosphate-buffered saline (PBS) $(0.05 \%$ Tween 20) three times, the non-specific binding sites were blocked with assay buffer (PBS-containing 10\% FBS) for $1 \mathrm{~h}$. After washing 3 times, $100 \mu \mathrm{L}$ sample and TNF- $\alpha$ standard were added to the corresponding wells and incubated at room temperature for $2 \mathrm{~h}$. After washing 5 times, $100 \mu \mathrm{L}$ detection antibody and Enzyme Reagent SAv-HRP diluted in assay buffer (1:250, respectively) 
were added to each well and incubated for $1 \mathrm{~h}$. After washing the wells 7 times, $100 \mu \mathrm{L}$ TMB substrate solution (1:1) was added to each well and incubated at room temperature in the dark. When a clear blue appeared, $50 \mu \mathrm{L}$ stop solution ( $2 \mathrm{M} \mathrm{H}_{2} \mathrm{SO}_{4}$ ) was added to each well. The final liquid was transferred in each well to a clean new 96-well plate, and the absorbance values were measured at an OD of $450 \mathrm{~nm}$ using spectrophotometer.

\section{Statistical Analysis}

All experiments were performed in triplicate and the data are presented as the mean \pm standard deviation (SD). IBM SPSS statistics 24 was performed using one-way analysis of variance (ANOVA) and Duncan's multiple range test (DMRT) to analyze statistical differences between the mean values $(P$ value $<0.05)$.

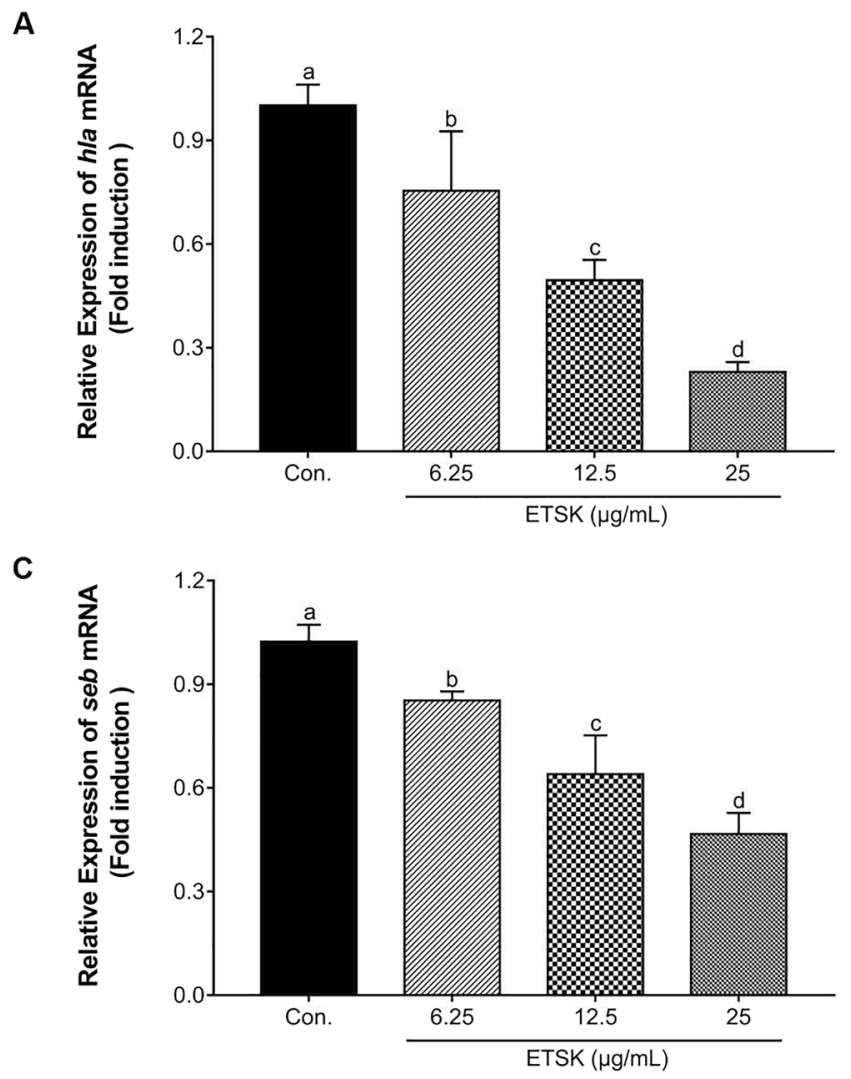

Fig. 1 Relative gene expression of hla (A), sea (B), seb (C), and agrA (D) in S. aureus ATCC 33,591 grown under graded sub-inhibitory concentrations $(6.25-25 \mu \mathrm{g} / \mathrm{mL})$ of ETSK was analyzed by quantitative RT-PCR (qRT-PCR). Values represent the means \pm SD of three independent experiments. Different letters indicate statistically significant differences $(P<0.05)$, while the same letters mean no signifi-

\section{Results}

\section{ETSK Represses the Transcription of $h l a$, sea, seb, and agrA Genes in S. aureus}

Quantitative reverse transcription PCR (qRT-PCR) was performed to investigate the effect of ETSK on the expression of genes encoding $\alpha$-hemolysin, SEA, and SEB. The agrA is a critical operon that regulates the transcription of these toxic factor genes. As shown in Fig. 1, upon treatment with ETSK at sub-MIC concentrations, the expression of sea, seb, hla, and agrA in ATCC 33,591 were significantly reduced in a dose-dependent manner. In the treatment group, the downward trend in gene expression of toxicity-related factors suggests that ETSK may prevent MRSA infection by inhibiting representative exotoxin produced by MRSA. Therefore, the next experiment aims to determine whether the protein translation process of these exotoxin is affected by ETSK as expected.

B

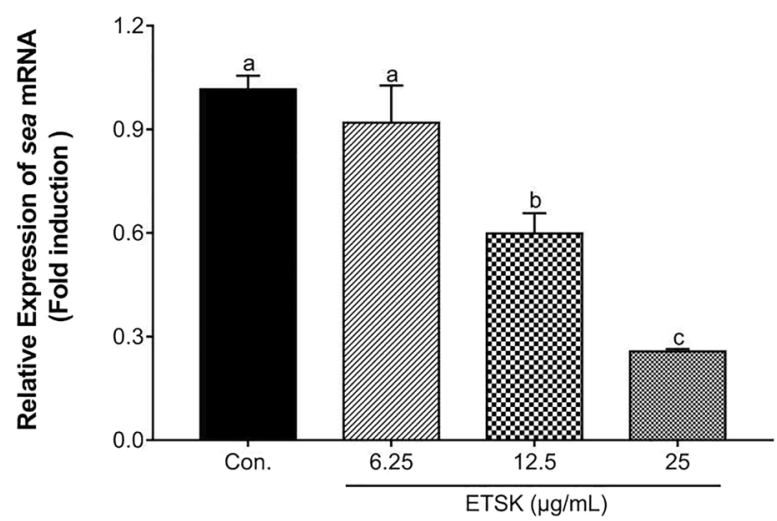

D

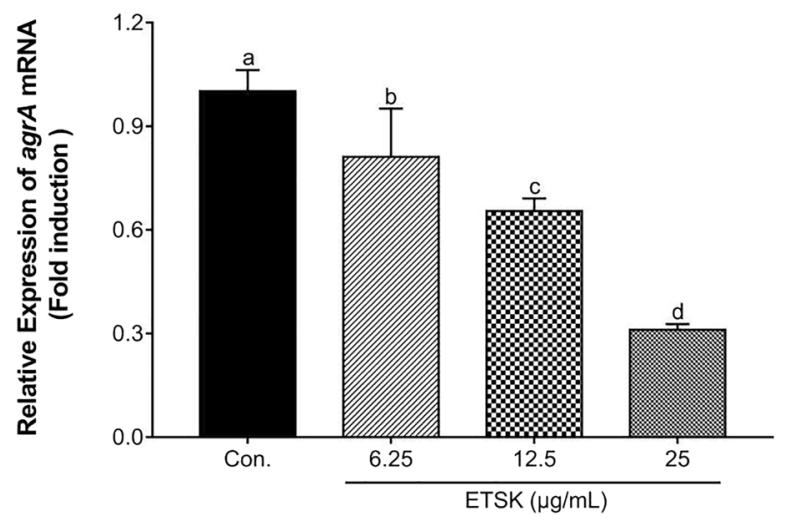

cant differences $(P>0.05)$. Con., control, untreated $S$. aureus strains; $h l a$, gene encoding $\alpha$-hemolysin; sea, gene encoding staphylococcal enterotoxin A; seb, gene encoding staphylococcal enterotoxin B; agrA, gene encoding accessory gene regulator A; ETSK, Eleutheroside $\mathrm{K}$ 


\section{ETSK Represses the Translation of a-hemolysin and Staphylococcal Enterotoxins in S. aureus}

The secretion of $\alpha$-hemolysin and staphylococcal enterotoxins by ATCC 33,591 exposed to sub-inhibitory concentrations of ETSK was determined by western blotting analysis. Figure 2 illustrates the expression of these three representative $S$. aureus exotoxins after treatment with ETSK for $4 \mathrm{~h}$. In the presence of sub-inhibitory concentrations of ESTK, although the dose-dependent manner is not obvious, it can be seen that the secretion of $\alpha$-hemolysin and SEA was significantly reduced compared with the untreated group. According to the western blot analysis of SEB, the inhibitory effect of ETSK on SEB is obviously dose-dependent. The original and un-cropped images of the results were presented in Suppl. Figure 2. These results reinforce the notion that the mechanism by which ETSK inhibits MRSA infection is related to the attenuation of $S$. aureus exotoxins expression by ETSK.

\section{ETSK Represses TNF-Inducing Activity of S. aureus}

Enzyme-linked immunosorbent assay (ELISA) was performed to evaluate the effect of ETSK on the production of pro-inflammatory cytokine TNF- $\alpha$. S. aureus infection can cause a series of inflammatory disorders. It has been reported that MRSA has the ability to induce the release of pro-inflammatory cytokines from $T$ cells [15]. SEs are important exotoxins produced by $S$. aureus and can act as superantigens to stimulate macrophages to produce cytokines. In order to verify the effect of ETSK on the inflammation of macrophage RAW 264.7 induced by $S$. aureus exotoxins, we tested the expression of the representative pro-inflammatory cytokine TNF- $\alpha$. Figure 3 depicts that the presence of MRSA culture supernatant triggers the massive release of TNF- $\alpha$ from RAW 264.7 compared with the normal blank control group. However, the culture supernatants of ATCC 33,591 grown under sub-inhibitory concentrations of ETSK apparently hampered TNF-inducing activity of $S$. aureus in a dose-dependent manner.
Fig. 2 The protein expression of $\alpha$-hemolysin, SEA, and SEB produced by ATCC 33,591 strain treated with the sub-inhibitory concentrations $(6.25-25 \mu \mathrm{g} / \mathrm{mL})$ of ETSK were analyzed by western blot. After $4 \mathrm{~h}$ of treatment, ETSK with graded sub-inhibitory concentrations suppressed the production of $\alpha$-hemolysin, SEA, and SEB. GAPDH was used as the loading control. Values represent the means \pm SD of three independent experiments. Different letters indicate statistically significant differences $(P<0.05)$, while the same letters mean no significant differences $(P>0.05)$. Con., control, untreated $S$. aureus strain; HLA, $\alpha$-hemolysin; SEA, staphylococcal enterotoxin A; SEB, staphylococcal enterotoxin B; GAPDH, glyceraldehyde 3-phosphate dehydrogenase; ETSK, Eleutheroside K
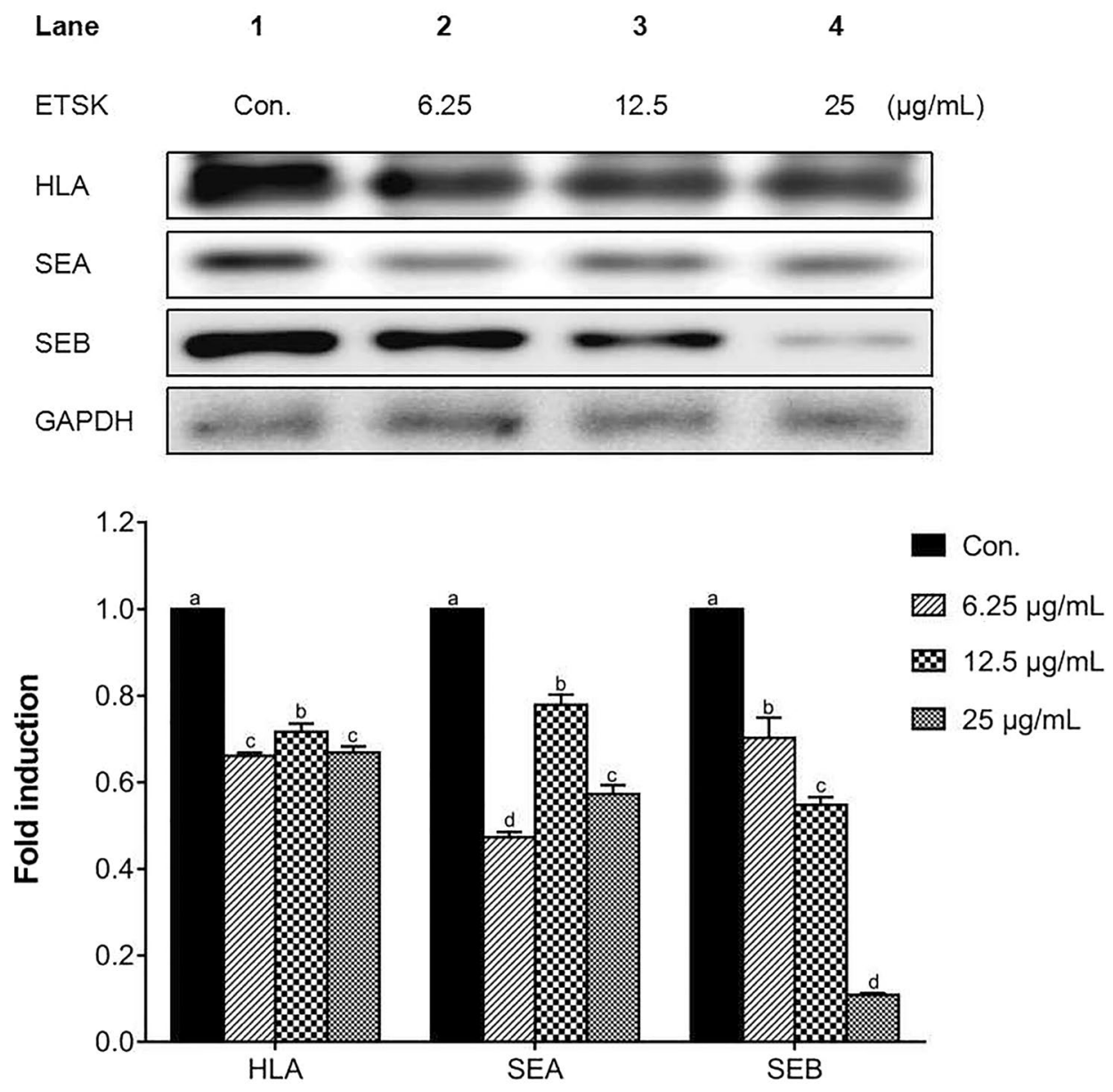


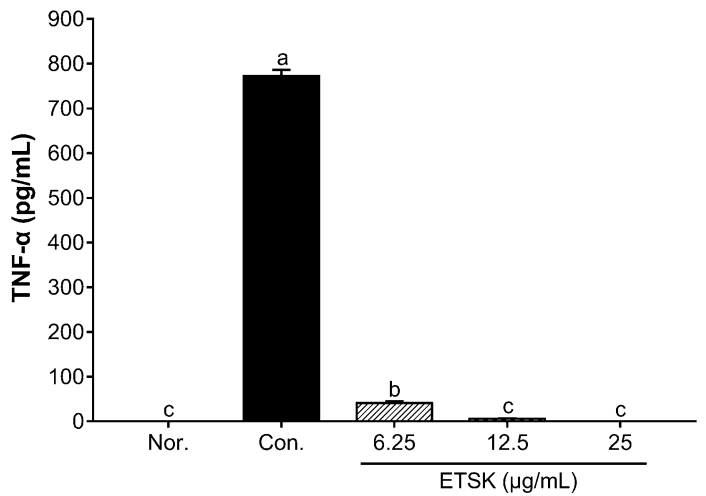

Fig. 3 Enzyme-linked immunosorbent assay (ELISA) analysis of tumor necrosis factor (TNF) released by RAW 264.7 cells stimulated with the supernatants of $S$. aureus grown in the presence of graded sub-inhibitory concentrations $(6.25-25 \mu \mathrm{g} / \mathrm{mL})$ of ETSK. Values represent the means \pm SD of three independent experiments. Different letters indicate statistically significant differences $(P<0.05)$, while the same letters mean no significant differences $(P>0.05)$. Nor., normal, blank control group; Con., control, untreated $S$. aureus strain; ETSK, Eleutheroside K

\section{Discussion}

S. aureus is a ubiquitous pathogen that can cause a wide spectrum of infectious diseases, including skin and soft tissue infections [27]. It is one of the main causes of bacterial infections worldwide [28]. Since the emergence of MRSA in 1961, there have been serious infection control problems [29]. The pathogenesis of MRSA is diverse. Manifold antibiotics mainly aimed at inhibiting the growth of $S$. aureus that have been developed and applied to treat $S$. aureus infections. However, due to the growing emergence of multi-drug-resistant bacteria, the development of effective antibacterial drugs or novel therapeutic approaches has become more urgent [30]. Additionally, the virulence factors produced by $S$. aureus enable the bacterial pathogens to engender various troublesome infections. These virulence factors (such as exotoxins and enzymes) can be superantigenic and can transform host tissues into nutrients needed for bacterial growth to help $S$. aureus pathogens survive under various conditions [26]. Also, many S. aureus can express adhesion molecules to make bacteria adhere to host cells, which promotes the formation of biofilms, making S. aureus infections increasingly difficult to treat [31]. In addition to inhibiting the essential processes of bacterial growth and survival, an innovative exploratory approach for ameliorating the condition is to find novel agents that target bacterial virulence factors. Studies related to the antibacterial activity and mechanism of plant extracts have been reported previously [32]. ETSK (oleanolic acid 3-O- $\alpha-\mathrm{L}^{-}$ rhamnopyranosyl-( $(\rightarrow 2)-\alpha$-L-arabinopyranoside), as an active oleanane-type triterpenoid saponin isolated from the leaves of the renowned medicinal plant $A$. henryi (Oliv.) Harms, has attracted our attention to study whether it has the ability to treat MRSA infections. Since ETSK bears a unique disaccharide moiety that induces cytotoxicity, it generally has significant anti-tumor activity [33]. Our earlier research on the effect of natural pharmaceutical compound ETSK on reversing the drug resistance caused by MRSA aroused our curiosity about the potential of ETSK in inhibiting the expression of related virulence factors. In the present study, we explored the medicinal mechanism of ETSK by investigating the inhibitory effect of ETSK on the synthesis of $S$. aureus exotoxins.

The $\alpha$-hemolysin is a crucial virulence factor secreted by the majority of $S$. aureus strains and can subvert the host immune system. As a cell membrane pore-forming toxin, $\alpha$-hemolysin is primarily responsible for the hemolytic activity of $S$. aureus and can engender tissue damage. In addition, in epithelial cells, the escape of $S$. aureus from endocytic vesicles into the cytosol requires $\alpha$-hemolysin [34]. The $\alpha$-hemolysin is widely known to induce cytotoxicity against a variety of cells and plays a predominant role in the pathogenesis of severe cases of pneumonia [35] Based on analysis of gene and protein level expression, in the untreated control group, the high expression of $\alpha$-hemolysin is very obvious. Compared with the control group, the protein and gene expression of $\alpha$-hemolysin were obviously diminished in the presence of sub-inhibitory concentrations of ETSK. However, the trend between transcription level and translation level is not completely consistent, which may be caused by the modification, transport, and degradation of mRNA during protein translation. In general, it can be concluded that the mechanism by which ETSK inhibits MRSA infection is probably attributed to the blockade of the main toxin product $\alpha$-hemolysin.

SEs have been recognized as bacterial superantigens that induce cellular proliferation, cytokine storm, and toxic shock syndrome [36]. Additionally, the emetic activity of SEs and the resistance to inactivation of SEs caused by gastrointestinal proteases have potential to trigger staphylococcal gastroenteritis and food poisoning in humans [34]. Due to these characteristics of SEs, research to effectively inhibit these exotoxin has become an urgent demand. Five major types based on serology (SEA to SEE) have been classified. Meanwhile, more than 20 distinct types of SEs with consensus sequence homology are known; however, only a few of them have been studied in depth. SEA and SEB are the most common SEs. SEA is the most usual cause that prompts staphylococcus-related food-borne poisoning, while SEB is also related to food poisoning and is assumed to be applied as an inhaled biological weapon [37]. According to our qRT-PCR and western blotting analysis results, ETSK has an inhibitory effect on the SEs gene and protein expression at sub-inhibitory concentrations. The salient inhibitory 
effect of ETSK on gene transcription and protein translation of MRSA virulence factors (such as $\alpha$-hemolysin and SEs) at sub-inhibitory concentrations indicates the potential of ETSK to be applied to the treatment of MRSA infections. The gene and protein expression of SEB showed consistent dose-dependent reduction. However, although the gene transcription and the protein translation of SEA were suppressed by ETSK, there is not a completely consistent weakening trend. As for the reason for this phenomenon, we speculate that, in addition to the possibility of related mRNA modification and degradation, there may also be some small mRNA regulation effects, such as miRNA, during protein translation. In addition, our research also attempted to explore the effect of ETSK on the agr system. In the presence of ETSK, the $\operatorname{agr} A$ was inhibited at the gene level in a dose-dependent manner. We speculate that ETSK suppresses the expression of genes encoding S. aureus exotoxin downstream of agrA by inhibiting the gene expression of the agr regulatory system. Due to the down-regulation of agrA gene expression, we have sufficient reasons to infer that the expression of $S$. aureus exotoxins regulated by RNAIII will be suppressed at both gene and protein levels [38, 39]. As a factor that activates RNAIII expression, the downward trend of $a g r A$ gene expression is consistent with the inhibition of $\alpha$-hemolysin and SEs as expected.

The SEs are the most important exotoxins of S. aureus that act as superantigens, which could induce the release of pro-inflammatory cytokines by $\mathrm{T}$ cells [14]. Therefore, to elucidate the biological relevance of reduced staphylococcal exotoxin secretion caused by ETSK, Enzyme-linked immunosorbent assay (ELISA) was performed to evaluate the effect of ETSK on the production of pro-inflammatory cytokine TNF- $\alpha$. The ability of ETSK to down-regulate TNF- $\alpha$ was observed in our present study. Compared to the untreated normal group, the plethora of TNF- $\alpha$ release is caused by the supernatant of $S$. aureus culture medium, while in the presence of culture supernatants of $S$. aureus grown under sub-inhibitory concentrations of ETSK, the content of TNF- $\alpha$ was substantially reduced dose dependently. This reduction of TNF- $\alpha$ released by RAW 264.7 suggests the potential of ETSK to treat the inflammation caused by MRSA infection. In addition to inhibiting the gene and protein expression of $S$. aureus exotoxins, we believe that ETSK also shows excellent anti-inflammatory ability [40]. From the molecular level, we speculate that the therapeutic effect of ETSK on inflammation is related to the inhibition of SEs by ETSK treatment. Since cytokines are released under the stimulation of SEs, the reduction of SEs can be inferred from the result of the diminished TNF-inducing ability. Based on the determination of the protein and gene expression of SEs, our conjecture is considered reliable.

According to the foregoing findings, the authors infer that ETSK may inhibit the production of exotoxin by S. aureus not only during protein translation but also at the level of gene transcription. ETSK significantly down-regulated the expression of virulence-related factors of $S$. aureus and the higher the concentration of ETSK, the greater its usefulness to impede the toxin production. In addition, this study also found that at a higher bacterial density $\left(\mathrm{OD}_{600 \mathrm{~nm}}=0.9\right)$, ETSK still showed a significant inhibitory effect on toxins produced by MRSA, even if the strains were subjected to less drug pressure. Overall, the present results suggest the potential of ETSK as a novel antibacterial compound for the prevention and control of serious and urgent MRSA infection.

\section{Conclusion}

This study was devoted to investigating the capability of ETSK isolated from the leaves of A. henryi (Oliv.) Harms to repress the virulence factors released by $S$. aureus. The results indicated that sub-inhibitory concentrations of ETSK impeded the protein and gene expression of $S$. aureus exotoxins, and it was even possible to reduce the ability of $S$. aureus to induce macrophages to release pro-inflammatory cytokines by inhibiting the exotoxin SEs. The hypothesis that ETSK has an inhibitory effect on the virulence-related exoproteins of MRSA has been confirmed. Therefore, we believe that ETSK can be used as an innovative antibacterial drug to ameliorate the intractable MRSA infection by hindering the production of exotoxins. Herein, we propose the concept that the natural plant compound ETSK possesses the ability to inhibit the toxicity of MRSA. In order for ETSK to be truly applied to the clinical treatment of difficult MRSA infections, more in-depth exploration and research on ETSK are needed.

Supplementary Information The online version contains supplementary material available at https://doi.org/10.1007/s00284-021-02631-5.

Acknowledgements This research was supported by the Wonkwang University in 2021.

Author Contributions Conceptualization, QQL, OHK, and DYK; methodology, QQL, OHK, and DYK; investigation, QQL; resources, JL and XQL; data curation, QQL; writing-original draft preparation, QQL; writing - review and editing, OHK and DYK; supervision, OHK; project administration, DYK. All authors have read and agreed to the published version of the manuscript.

Data Availability The data used or analyzed during the present study are available from the corresponding author on reasonable request.

\section{Declarations}

Conflict of interest The authors declare that they have no conflict of interest. 
Consent to Publication All authors have read and agreed to the published version of the manuscript.

Open Access This article is licensed under a Creative Commons Attribution 4.0 International License, which permits use, sharing, adaptation, distribution and reproduction in any medium or format, as long as you give appropriate credit to the original author(s) and the source, provide a link to the Creative Commons licence, and indicate if changes were made. The images or other third party material in this article are included in the article's Creative Commons licence, unless indicated otherwise in a credit line to the material. If material is not included in the article's Creative Commons licence and your intended use is not permitted by statutory regulation or exceeds the permitted use, you will need to obtain permission directly from the copyright holder. To view a copy of this licence, visit http://creativecommons.org/licenses/by/4.0/.

\section{References}

1. Stefani S, Chung DR, Lindsay JA, Friedrich AW, Kearns AM, Westh H, Mackenzie FM (2012) Meticillin-resistant Staphylococcus aureus (MRSA): global epidemiology and harmonisation of typing methods. Int J Antimicrob Agents 39(4):273-282. https:// doi.org/10.1016/j.ijantimicag.2011.09.030

2. Lowy FD (1998) Staphylococcus aureus infections. N Engl J Med 339(8):520-532. https://doi.org/10.1056/NEJM199808203390806

3. Xue L, Chen YY, Yan Z, Lu W, Wan D, Zhu H (2019) Staphyloxanthin: a potential target for antivirulence therapy. Infect Drug Resist 12:2151-2160. https://doi.org/10.2147/IDR.S193649

4. Bassous NJ, Webster TJ (2019) The binary effect on methicillin-resistant Staphylococcus aureus of polymeric nanovesicles appended by proline-rich amino acid sequences and inorganic nanoparticles. Small 15(18):e1804247. https://doi.org/10.1002/ smll.201804247

5. Pillai MM, Latha R, Sarkar G (2012) Detection of methicillin resistance in Staphylococcus aureus by polymerase chain reaction and conventional methods: a comparative study. J Lab Physicians 4(2):83-88. https://doi.org/10.4103/0974-2727.105587

6. Long N, Tang H, Sun F, Lin L, Dai M (2019) Effect and mechanism of citral against methicillin-resistant Staphylococcus aureus in vivo. J Sci Food Agric 99(9):4423-4429. https://doi.org/10. $1002 /$ jsfa. 9677

7. Udo EE, Boswihi SS (2017) Antibiotic resistance trends in methicillin-resistant Staphylococcus aureus isolated in Kuwait hospitals: 2011-2015. Med Princ Pract 26(5):485-490. https://doi.org/ $10.1159 / 000481944$

8. Abbas HA, Elsherbini AM, Shaldam MA (2017) Repurposing metformin as a quorum sensing inhibitor in Pseudomonas aeruginosa. Afr Health Sci 17(3):808-819. https://doi.org/10.4314/ ahs.v17i3.24

9. Ohlsen K, Koller KP, Hacker J (1997) Analysis of expression of the alpha-toxin gene (hla) of Staphylococcus aureus by using a chromosomally encoded hla::lacZ gene fusion. Infect Immun 65(9):3606-3614. https://doi.org/10.1128/iai.65.9.3606-3614. 1997

10. Tseng CW, Stewart GC (2005) Rot repression of enterotoxin B expression in Staphylococcus aureus. J Bacteriol 187(15):53015309. https://doi.org/10.1128/JB.187.15.5301-5309.2005

11. Kong C, Neoh HM, Nathan S (2016) Targeting Staphylococcus aureus toxins: a potential form of anti-virulence therapy. Toxins 8(3):72. https://doi.org/10.3390/toxins8030072

12. Gong J, Li D, Yan J, Liu Y, Li D, Dong J, Gao Y, Sun T (2014) The accessory gene regulator (agr) controls Staphylococcus aureus virulence in a murine intracranial abscesses model. Braz J Infect Dis 18(5):501-506. https://doi.org/10.1016/j.bjid.2014. 03.005

13. Jiang B, Yin S, You B, Gong Y, Huang G, Yang Z, Zhang Y, Chen Y (2018) Antimicrobial resistance and virulence genes profiling of methicillin-resistant Staphylococcus aureus isolates in a burn center: a 5-year study. Microb Pathog 114:176-179. https://doi. org/10.1016/j.micpath.2017.11.020

14. Qiu J, Wang J, Luo H, Du X, Li H, Luo M, Dong J, Chen Z (2011) The effects of subinhibitory concentrations of costus oil on virulence factor production in Staphylococcus aureus. J Appl Microbiol 110(1):333-340. https://doi.org/10.1111/j.1365-2672. 2010.04888.x

15. Qiu J, Wang D, Xiang H, Feng H, Jiang Y, Xia L, Dong J, Lu J (2010) Subinhibitory concentrations of thymol reduce enterotoxins A and B and alpha-hemolysin production in Staphylococcus aureus isolates. PLoS ONE 5(3):e9736. https://doi.org/10.1371/ journal.pone.0009736

16. Hoseini Alfatemi SM, Motamedifar M, Hadi N, Sedigh Ebrahim Saraie H (2014) Analysis of virulence genes among methicillin resistant Staphylococcus aureus (MRSA) strains. Jundishapur J Microbiol 7(6):e10741. https://doi.org/10.5812/jjm.10741

17. Cheung GY, Wang R, Khan BA, Sturdevant DE, Otto M (2011) Role of the accessory gene regulator agr in community-associated methicillin-resistant Staphylococcus aureus pathogenesis. Infect Immun 79(5):1927-1935. https://doi.org/10.1128/IAI.00046-11

18. Mansell A, Jenkins BJ (2013) Dangerous liaisons between interleukin- 6 cytokine and toll-like receptor families: a potent combination in inflammation and cancer. Cytokine Growth Factor Rev 24(3):249-256. https://doi.org/10.1016/j.cytogfr.2013.03.007

19. Hou M, Zhang N, Yang J, Meng X, Yang R, Li J, Sun T (2013) Antimicrobial peptide LL-37 and IDR-1 ameliorate MRSA pneumonia in vivo. Cell Physiol Biochem 32(3):614-623. https://doi. org/10.1159/000354465

20. Park SY, Yook CS, Nohara T, Mizutani T, Tanaka T (2004) Random amplified polymorphic DNA analysis of genetic relationships among Acanthopanax species. Arch Pharm Res 27(12):12701274. https://doi.org/10.1007/BF02975893

21. Kim JH, Liu XQ, Dai L, Yook CS, Lee KT (2014) Cytotoxicity and anti-inflammatory effects of root bark extracts of Acanthopanax henryi. Chin J Nat Med 12(2):121-125. https://doi.org/10. 1016/S1875-5364(14)60019-4

22. Zhang XD, Liu XQ, Kim YH, Whang WK (2014) Chemical constituents and their acetyl cholinesterase inhibitory and antioxidant activities from leaves of Acanthopanax henryi: potential complementary source against Alzheimer's disease. Arch Pharm Res 37(5):606-616. https://doi.org/10.1007/s12272-013-0252-x

23. Seo YS, Lee SJ, Li Z, Kang OH, Kong R, Kim SA, Zhou T (2017) Araliasaponin II isolated from leaves of Acanthopanax henryi (Oliv.) harms inhibits inflammation by modulating the expression of inflammatory markers in murine macrophages. Mol Med Rep 16(1):1791-1797. https://doi.org/10.3892/mmr.2017.6656

24. Li QQ, Luo J, Liu XQ, Kwon DY, Kang OH (2020) Eleutheroside $\mathrm{K}$ isolated from Acanthopanax henryi (Oliv.) harms suppresses methicillin resistance of Staphylococcus aureus. Lett Appl Microbiol 72(6):669-676. https://doi.org/10.1111/lam.13389

25. Zhang XD, Li Z, Liu GZ, Wang X, Kwon OK, Lee HK, Whang WK, Liu XQ (2016) Quantitative determination of 15 bioactive triterpenoid saponins in different parts of Acanthopanax henryi by HPLC with charged aerosol detection and confirmation by LC-ESI-TOF-MS. J Sep Sci 39(12):2252-2262. https://doi.org/ $10.1002 /$ jssc. 201501029

26. Mun SH, Kong R, Seo YS, Zhou T, Kang OH, Shin DW, Kwon DY (2016) Subinhibitory concentrations of punicalagin reduces expression of virulence-related exoproteins by Staphylococcus 
aureus. FEMS Microbiol Lett 363(22):fnw253. https://doi.org/ 10.1093/femsle/fnw253

27. Zhang W, Zhuo S, He L, Cheng C, Zhu B, Lu Y, Wu Q, Shang W, Ge W, Shi L (2019) Daphnetin prevents methicillin-resistant Staphylococcus aureus infection by inducing autophagic response. Int Immunopharmacol 72:195-203. https://doi.org/10.1016/j. intimp.2019.04.007

28. Braga ED, Aguiar-Alves F, de Freitas MDFN, de eSilva MO, Correa TV, Snyder RE, de Araújo VA, Marlow MA (2014) High prevalence of Staphylococcus aureus and methicillin-resistant $S$. aureus colonization among healthy children attending public daycare centers in informal settlements in a large urban center in Brazil. BMC Infect Dis 14:538. https://doi.org/10.1186/ 1471-2334-14-538

29. Dean MA, Olsen RJ, Long SW, Rosato AE, Musser JM (2014) Identification of point mutations in clinical Staphylococcus aureus strains that produce small-colony variants auxotrophic for menadione. Infect Immun 82(4):1600-1605. https://doi.org/10.1128/ IAI.01487-13

30. Zhou T, Li Z, Kang OH, Mun SH, Seo YS, Kong R, Shin DW, Liu XQ, Kwon DY (2017) Antimicrobial activity and synergism of ursolic acid 3-O- $\alpha$-L-arabinopyranoside with oxacillin against methicillin-resistant Staphylococcus aureus. Int J Mol Med 40(4):1285-1293. https://doi.org/10.3892/ijmm.2017.3099

31. Zhou B, Zhang D (2018) Antibacterial effects of bacteriocins isolated from Lactobacillus rhamnosus (ATCC 53103) in a rabbit model of knee implant infection. Exp Ther Med 15(3):2985-2989. https://doi.org/10.3892/etm.2018.5790

32. Li HN, Wang CY, Wang CL, Chou CH, Leu YL, Chen BY (2019) Antimicrobial effects and mechanisms of ethanol extracts of Psoralea corylifolia seeds against Listeria monocytogenes and methicillin-resistant Staphylococcus aureus. Foodborne Pathog Dis 16(8):573-580. https://doi.org/10.1089/fpd.2018.2595

33. Cheng MS, Yan MC, Liu Y, Zheng LG, Liu J (2006) Synthesis of beta-hederin and hederacolchiside A1: triterpenoid saponins bearing a unique cytotoxicity-inducing disaccharide moiety. Carbohydr Res 341(1):60-67. https://doi.org/10.1016/j.carres.2005. 10.015
34. Koziel J, Chmiest D, Bryzek D, Kmiecik K, Mizgalska D, Maciag-Gudowska A, Shaw LN, Potempa J (2015) The janus face of $\alpha$-toxin: a potent mediator of cytoprotection in staphylococciinfected macrophages. J Innate Immun 7(2):187-198. https://doi. org $/ 10.1159 / 000368048$

35. Smith-Palmer A, Stewart J, Fyfe L (2004) Influence of subinhibitory concentrations of plant essential oils on the production of enterotoxins A and B and alpha-toxin by Staphylococcus aureus. J Med Microbiol 53(Pt 10):1023-1027. https://doi.org/10.1099/ jmm.0.45567-0

36. Huang TM, Chou CC (2019) Methicillin-sensitive and methicillinresistant Staphylococcus aureus strains and their toxin genes in the nostrils of dogs and workers at an animal shelter. J Appl Microbiol 126(6):1899-1909. https://doi.org/10.1111/jam.14266

37 Pinchuk IV, Beswick EJ, Reyes VE (2010) Staphylococcal enterotoxins. Toxins 2(8):2177-2197. https://doi.org/10.3390/toxin s2082177

38. Sonoda S, Yamaguchi T, Aoki K, Ono D, Sato A, Kajiwara C, Kimura S, Akasaka Y (2018) Evidence of latent mETSKcular diversity determining the virulence of community-associated MRSA USA300 clones in mice. Immun Inflamm Dis 6(3):402412. https://doi.org/10.1002/iid3.234

39. Vire FP, Akpaka PE, Unakal C (2018) Molecular characterization of methicillin-resistant Staphylococcus aureus isolates from rural community settings in trinidad and tobago. Niger J Clin Pract 21(12):1596-1601. https://doi.org/10.4103/njcp.njcp_269_18

40. Hwang SA, Kruzel ML, Actor JK (2014) Immunomodulatory effects of recombinant lactoferrin during MRSA infection. Int Immunopharmacol 20(1):157-163. https://doi.org/10.1016/j. intimp.2014.02.029

Publisher's Note Springer Nature remains neutral with regard to jurisdictional claims in published maps and institutional affiliations. 